\title{
Should medical errors ever be considered criminal offences?
}

\author{
口 Cite as: CMAJ 2018 April 23;190:E518-9. doi: 10.1503/cmaj.109-5588
}

Posted on cmajnews.com on Apr. 5, 2018.

anadian doctors continue to follow the developments in the case of Dr. Hadiza Bawa-Garba, a junior doctor in the United Kingdom found guilty of manslaughter after a young boy under her care died because of medical error and systemic shortcomings. In late March, she was given a chance to appeal a ruling by the General Medical Council that saw her stripped of her medical licence.

Medical residents in Canada are especially troubled that evidence used against Bawa-Garba included her honest reflections about how the mistake could have been prevented, said Dr. Melanie Bechard, president of Resident Doctors of Canada. It's a blow to the profession's promotion over the past decade of "an open dialogue and open-reflection culture that has helped us identify a lot of systemic factors and hopefully fix them very quickly."

"She was by herself in the night, covering the jobs of multiple people who were unable to be present, and to see those systemic factors underplayed compared to the role of one person is really concerning," added Bechard.

Bechard also worries that the possibility of a criminal conviction could make residents feel more hesitant about doing procedures and making decisions on their own, lest they be blamed for errors. Many training programs are in large, tertiary care centres, and residents nervous about expanding their boundaries may end up leaning too heavily on senior colleagues. "I would worry that cases like this can shift the balance to more hesitancy, and residents will come out of training without many of the skills that are absolutely essential to practise independently and safely."
Many Canadian doctors, especially residents, have asked the Canadian Medical Protective Association (CMPA) if they're vulnerable to similar criminal charges, according to Dr. Doug Bell, managing director of safe medical care for CMPA. Based on past experience, it's unlikely that Canadian courts would have treated the cases of criminal negligence causing death against Canadian health care providers in the past 25 years, but only one, against a pharmacist, resulted in a conviction. Prosecutors in Canada have to prove that physicians were deliberate or "went out of their way" to harm or end a life. "The reality is people just don't do that," he said.

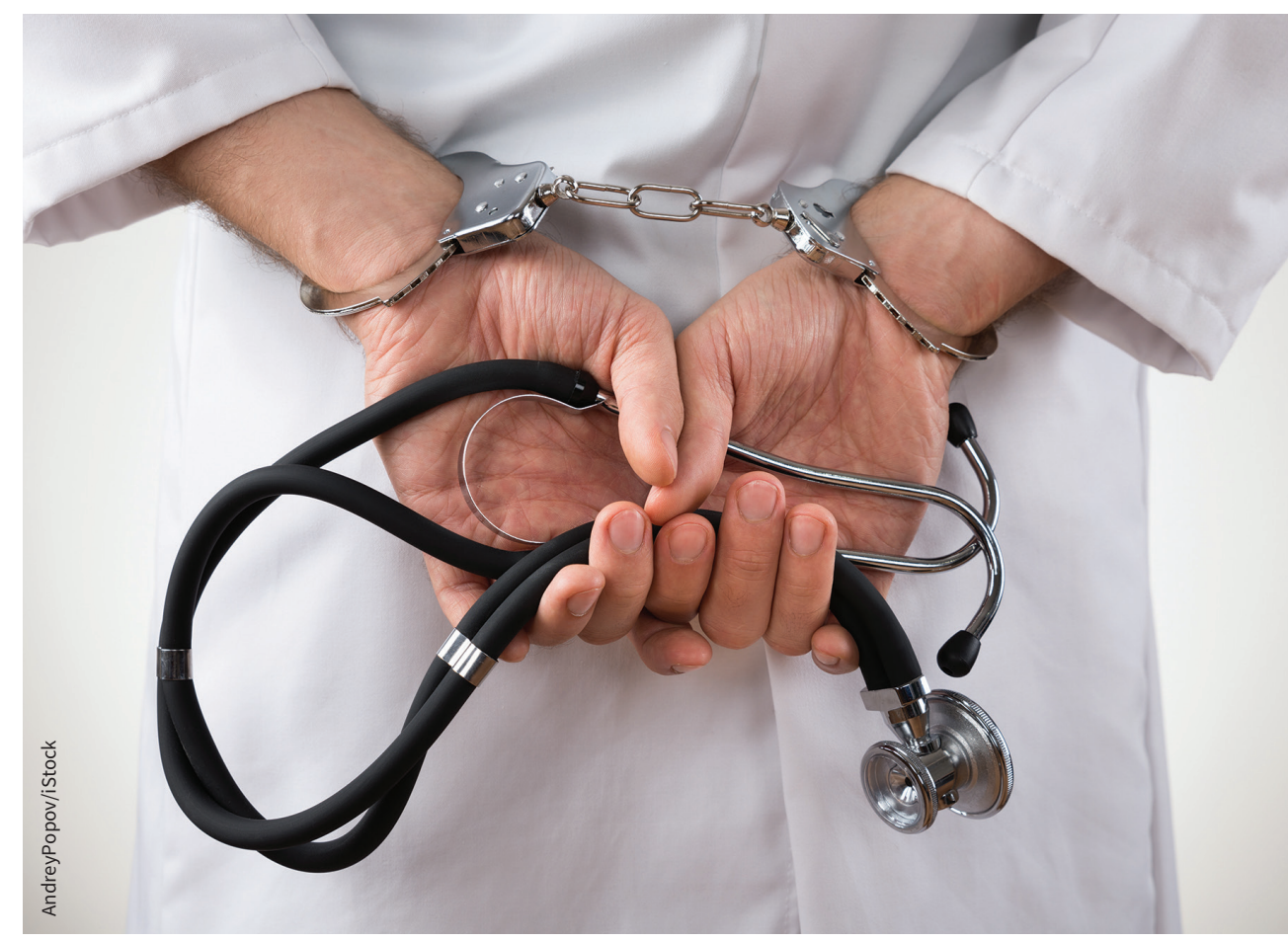

A manslaughter case against a UK junior doctor has Canadian physicians, especially residents, wondering if they could be vulnerable to similar charges.

Bawa-Garba case the same way, said Bell. "These laws have been on the books, but there just haven't been criminal charges laid against trainees," he said. "The prosecutors have chosen not to be aggressive."

Bell said he isn't aware of a physician being charged with manslaughter in Canada as a result of provision of medical care since 1990 . There have been three
Ken Berger, a lawyer who represents physicians, added that a case would become criminal in Canada only if there is "proof beyond a reasonable doubt" that the physician "showed a wanton or reckless disregard for the life or safety of the other person."

"It would have to be something like the Dr. Conrad Murray case," he added, 
referring to the American doctor found guilty of involuntary manslaughter after treating Michael Jackson's insomnia with propofol, a powerful sedative never intended for use as a sleep aid. In Canada, cases involving medical errors similar to Bawa-Garba's case would be "dealt with in the tort law system ... it would not go into criminal law context," said Berger.

Dr. Albert Wu, a general internist in Baltimore, Maryland, who studies adverse events and quality improve- ment, agreed that criminal charges are unfair in cases of medical error. "Criminal charges are only appropriate when there's deliberate malfeasance or gross negligence - for example, if someone left their station and spent half the shift in the pub," he said.

The manslaughter decision against Bawa-Garba, and subsequent retraction of her licence, "decreased morale in a group of registrars that are already feeling beleaguered," said Wu. He noted that UK junior doctors receive less supervision than trainees in the US and Canada.

There's also concern that BawaGarba has taken the brunt of the blame for a child's death because she was junior. "In a system where there is not appropriate accountability at multiple levels of the system, it's easier to push responsibility down to the lowest person," said Wu.

Wendy Glauser, Toronto, Ont. 